\title{
Molecular-targeted therapies for ovarian cancer
}

\author{
Junzo Kigawa
}

Received: 17 July 2012/Published online: 28 August 2012

(C) Japan Society of Clinical Oncology 2012

The incidence of ovarian cancer in 2008 was projected to be 225,500 new cases and 140,200 deaths worldwide, representing $3.7 \%$ of all female cancers and $4.2 \%$ of all cancer deaths in women [1]. Ovarian cancer, one of the major causes of death from cancer in women, is commonly diagnosed at advanced stage [2]. Cytoreductive surgery followed by platinum and taxane-based combination chemotherapy is currently the standard treatment for ovarian cancer [3]. However, most patients ultimately recur and develop chemo-resistance. An international study, GOG 182-ICON 5, sought to improve the efficacy of standard platinum-taxane therapy by incorporating newer cytotoxic agents (gemcitabine, pegylated liposomal doxorubicin, and topotecan) [4]. However, the combination of these agents used in standard therapy has not improved overall survival. A new strategy is needed to improve the prognosis of patients with ovarian cancer.

With recent molecular biological progress, moleculartargeted agents have been developed. The targets range over a vascularization, a growth factor and the receptor, a signal transduction system, DNA restoration, and so on. Some molecular-targeted agents have already been widely used for lung cancer or colon cancer. On the other hand, molecular-targeted agents are not clinically usable for gynecologic malignancies. Recently, molecular-targeted therapies for ovarian cancer, including signal-transduction inhibitors, anti-angiogenesis, and gene therapies, have been developed and several clinical trials have been performed for ovarian cancer [5, 6]. Unfortunately, molecular-targeted agents alone have been insufficient to improve the prognosis for advanced ovarian cancer, and biological target therapies should be employed together with conventional cytotoxic agents. When using molecular-targeted agents, we must be alert to the appearance of unexpected adverse effects [7]. Additionally, cost-effectiveness should be an important issue. Because tailor-made treatment based on the characteristics of the cancer cell is anticipated, translational research for biomarkers is necessary.

Here, basic research and clinical trials of moleculartargeted therapy for ovarian cancer are reviewed in the following two invited review articles.

Conflict of interest I have no conflict of interest.

\section{References}

1. http://www.cancer.org/Research/CancerFactsFigures/GlobalCancer FactsFigures/global-facts-figures-2nd-ed

2. FIGO annual report (2006) Int J Gynecol Obstet 95 Suppl:161-192

3. Japanese society of gynecologic oncology (2010) Ovarian cancer treatment guideline

4. Bookman MA, Brady MF, McGuire WP et al (2009) Evaluation of new platinum-based treatment regimens in advanced-stage ovarian cancer: a Phase III Trial of the Gynecologic Cancer Intergroup. J Clin Oncol 27:1419-1425

5. Kigawa J (2011) Relevance of genetic and epigenetic changes to treatment. Chemotherapeutic strategies for gynecologic cancers, pp 5-19

6. Itamochi $\mathrm{H}$ (2010) Targeted therapies in epithelial ovarian cancer: molecular mechanisms of action. World J Biol Chem 1:209-220

7. Punt CJ, Mol L, Koopman M (2011) Bevacizumab and cancer treatment-related mortality. JAMA 2011(305):2292-2293

J. Kigawa $(\bowtie)$

Department of Obstetrics and Gynecology, Tottori University,

36-1 Nishicho, Yonago 683-8504, Japan

e-mail: kigawa@med.tottori-u.ac.jp 